\title{
Production of Nitrogen-containing Carbon Plasma using Shunting Arc Discharge for Carbon Nitride Films Preparation
}

\author{
Keigo Imanishi Student Member (Iwate University) \\ Osamu Kumagai Non-member (Hitachi Plant Technologies) \\ Seiji Mukaigawa Member (Iwate University) \\ Kouichi Takaki Member (Iwate University) \\ Tamiya Fujiwara Member (Iwate University) \\ Ken Yukimura Member (Doshisya University) \\ Yoshiyuki Suda Member (Hokkaido University)
}

Keywords : arc discharge, shunting arc, hybrid plasma, plasma-based ion implantation, carbon nitride thin film

A shunting arc is a pulsed plasma source of solid-state materials such as titanium and carbon. The shunting arc can be easily generated at wide gas pressure range from vacuum to atmospheric gas pressure. The Plasma-based ion implantation \& deposition (PBII\&D) using a carbon shunting arc discharge in nitrogen gas circumstances is one of candidate to prepare carbon nitride $\left(\mathrm{CN}_{\mathrm{x}}\right)$ films. This paper describes characteristics of the shunting arc plasma produced in nitrogen gas circumstance, and amorphous carbon nitride $\left(\mathrm{a}-\mathrm{CN}_{\mathrm{x}}\right)$ films prepared using the shunting arc plasma containing nitrogen.

A schematic diagram of the experimental facilities is shown in Fig.1. A magnetically driven shunting arc generation unit was mounted in the vacuum chamber. A carbon rod with a diameter of $2 \mathrm{~mm}$ and a length of $40 \mathrm{~mm}$ held vertically between a pair of carbon electrode. A $20 \mu \mathrm{F}$ capacitor bank connected carbon electrodes was used to initiate a shunting arc. For film preparation using carbon shunting arc plasma, a disk target with $64 \mathrm{~mm}$ diameter and $11 \mathrm{~mm}$ thickness was set at $100 \mathrm{~mm}$ away from the carbon rod. Chips of silicon were mounted on the target. In order to extract ion from the plasma to a target, a negative high voltage pulse was applied to the target synchronizing with the generation of the shunting arc. The delay time between the shunting arc generation and the high voltage pulse application is control by delay pulse generator and fixed to $100 \mu \mathrm{s}$.

Figure 2 shows the rod heating energy to generate shunting arc and the onset voltage of the shunting arc as a function of ambient nitrogen gas pressure at charging voltage of $1.2 \mathrm{kV}$. The rod heating energy and the arc onset voltage have V-shape characteristics. The rod heating energy decreases from 0.63 to $0.024 \mathrm{~J}$ with increasing gas pressure from 0.02 to $40 \mathrm{~Pa}$ and then increases to about $0.058 \mathrm{~J}$ with increasing gas pressure to $100 \mathrm{~Pa}$. Minimum value of the arc on set voltage is $0.6 \mathrm{kV}$ at nitrogen gas pressure of $60 \mathrm{~Pa}$.

Figure 3 shows the $\mathrm{C}(1 \mathrm{~s})$ and $\mathrm{N}(1 \mathrm{~s})$ XPS spectra of the prepared carbon films for two different ambient nitrogen gas pressures. With injecting nitrogen gas, the energy at $C(1 \mathrm{~s})$ peak shifts from binding energy (BE) of $\mathrm{C}-\mathrm{C}$ to that of $\mathrm{sp}^{2} \mathrm{C}-\mathrm{N}$ and $\mathrm{sp}^{3} \mathrm{C}-\mathrm{N}$. The peak in $\mathrm{N}(1 \mathrm{~s})$ spectrum appears by employing nitrogen as ambient gas. It is found that when the carbon shunting arc generate in nitrogen gas, the prepared carbon film contain nitrogen. N/C ratio of film prepared in ambient pressure $2 \mathrm{~Pa}$ is 0.35 .

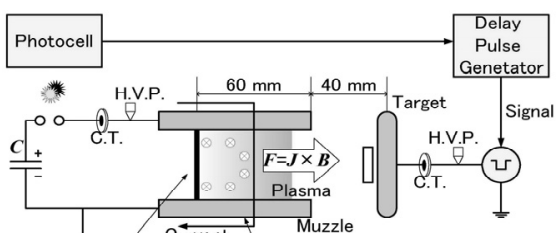

Fig. 1. Experimental setup

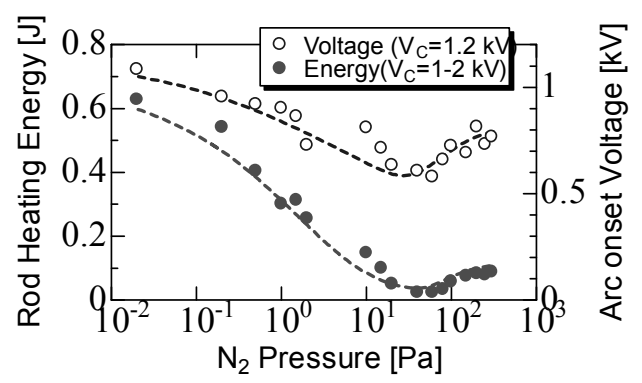

Fig. 2. Arc onset voltage and heating energy as a function of $\mathrm{N}_{2}$ gas pressure

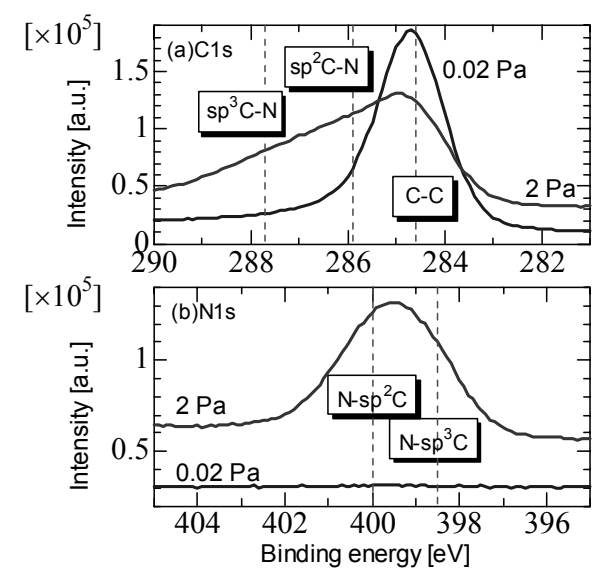

Fig. 3. XPS spectra of carbon films prepared at different ambient $\mathrm{N}_{2}$ gas pressures 


\title{
Production of Nitrogen-containing Carbon Plasma using Shunting Arc Discharge for Carbon Nitride Films Preparation
}

\author{
Keigo Imanishi* \\ Student Member \\ Osamu Kumagai** \\ Non-member \\ Seiji Mukaigawa* \\ Member \\ Koichi Takaki* \\ Member \\ Tamiya Fujiwara* \\ Member \\ Ken Yukimura*** \\ Member \\ Yoshiyuki Suda**** Member
}

\begin{abstract}
A magnetically driven carbon shunting arc discharge was generated in nitrogen gas circumstance and amorphous carbon nitride $\left(\mathrm{a}-\mathrm{CN}_{\mathrm{x}}\right)$ films were prepared using plasma-based ion implantation technique. A silicon substrate was immersed into the plasma, and a series of pulse voltage was applied to the substrate synchronizing with an ignition of the shunting arc with a peak current of $2.1 \mathrm{kA}$. The ambient nitrogen gas pressure was varied from 0.02 to $2 \mathrm{~Pa}$. The shunting arc plasma was successfully produced and was accelerated along carbon rails. Rod heating energy to generate the shunting arc had the minimum value for variation of the ambient gas pressure. A spectroscopic measurement from the plasma light emission showed that the produced plasma contained nitrogen particles in ambient nitrogen gas circumstance. X-ray photoelectron spectroscopy analysis showed that the prepared carbon films contained nitrogen and was obtained to be N/C ratio of 0.35 at $2 \mathrm{~Pa}$ nitrogen gas pressure.
\end{abstract}

Keywords : arc discharge, shunting arc, hybrid plasma, plasma-based ion implantation, carbon nitride thin film

\section{Introduction}

A shunting arc is a pulsed plasma source of solid-state materials such as titanium, tungsten, silicon and carbon. The shunting arc ignited by self-heating of the rod material to increase the vapor pressure and/or to emit thermoelectrons around the material, which is connected to a capacitor as a current source ${ }^{(1)}$. Since the shunting arc system consists of simple components, it promises to be a cost-effective technology. The shunting arc plasma is generated using evaporation from the rod heated by a pulsed current $^{(2)-(4)}$. This method does not require any ambient gas species like a sputtering technique. Moreover, the shunting arc can be generated without any triggering system because of self-ignition by pulse large current. This fact is one of the advantages over a conventional cathodic vacuum arc system. Therefore, the shunting arc is one of a promising method to prepare the droplet-free films ${ }^{(1)}$.

The plasma-based ion implantation \& deposition (PBII\&D) using the shunting arc with a carbon rod as an ion source have been used for diamond-like carbon (DLC) film deposition ${ }^{(5)}$. The experimental results show that the carbon layer was deposited on the silicon substrate with the deposition rate of $1 \mathrm{~nm} / \mathrm{min}$ and amorphous structure was confirmed in the deposited film using

* Iwate University

4-3-5, Ueda, Morioka 020-8551

** Hitachi Plant Technologies Co., Inc.

1-1-14, Uchikanda, Chiyoda-ku, Tokyo 101-0047

*** Doshisya University

1-3, Tatara, Miyakodani, Kyotanabe, Kyoto 610-0394

***** Hokkaido University

North 14 West 9, Kita-ku, Sapporo 060-8628
Raman spectra ${ }^{(6)}$. One reason of the low deposition rate of 1 $\mathrm{nm} / \mathrm{min}$ is that the plasma spreads out from the source rod towards an omni-direction ${ }^{(6)}$. For improvement of deposition rate, a magnetically driven shunting arc using a pair of carbon electrodes has been newly developed ${ }^{(7)}$. The deposition rate of DLC film was increased to $100 \mathrm{~nm} / \mathrm{min}$ by the magnetically driven shunting $\operatorname{arc}^{(8)(9)}$.

A recent trend of PBII\&D is a hybrid process containing deposition and ion implantation. Metallic plasma sources play important role of the process, and reactive deposition is also desirable to prepare various films to suit each industrial usage. The shunting arc discharge in various ambient gas circumstances is expected to product compound films. In previous studies, the carbon shunting arc plasma was produced in nitrogen gas and stationary RF nitrogen plasma ${ }^{(10)}$. The carbon shunting arc discharge in ambient nitrogen gas and nitrogen plasma is one of a candidate to prepare amorphous carbon nitride $\left(\mathrm{a}-\mathrm{CN}_{\mathrm{x}}\right)$ films. $\mathrm{CN}_{\mathrm{x}}$ is a promising material for electronics and mechanical technology because of its excellent properties, such as high hardness, low coefficient of friction and high thermal conductivity. Since Liu and Cohen predicted that metastable compound $\beta-\mathrm{C}_{3} \mathrm{~N}_{4}$ could have a higher bulk modulus than diamond ${ }^{(11)}$, the research in the field of carbon nitride has become active.

In this paper, carbon shunting arc discharges are produced in nitrogen gas circumstance, and electrical characteristics of the shunting arc plasma are described. a- $\mathrm{CN}_{\mathrm{x}}$ films are prepared using the shunting arc plasma containing nitrogen. The properties of the film measured with X-ray photoelectron spectroscopy (XPS) analysis are also described to clarify nitrogen content in the film. 


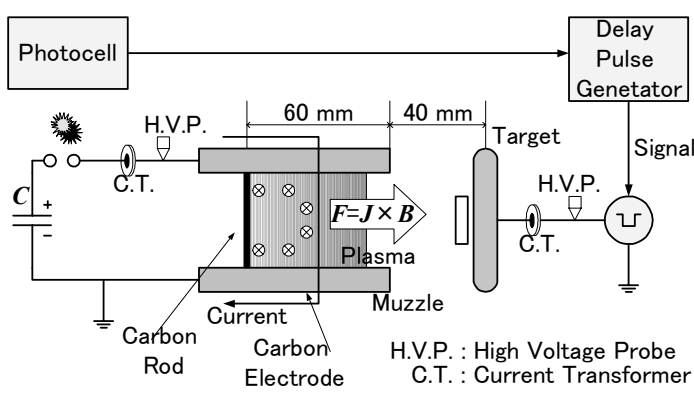

Fig. 1. Experimental setup

\section{Experimental Procedures}

A schematic diagram of the experimental facilities is shown in Fig.1. A cylindrical vacuum chamber with $1000 \mathrm{~mm}$ long and 800 $\mathrm{mm}$ inner diameter was evacuated up to $2 \times 10^{-2} \mathrm{~Pa}$ with a diffusion pump and a rotary pump. A magnetically driven shunting arc generation unit was mounted in the vacuum chamber. A carbon rod with a diameter of $2 \mathrm{~mm}$ and a length of $40 \mathrm{~mm}$ was held vertically between a pair of carbon rail electrodes. The resistance of the rail electrodes and the carbon rod used in shunting arc generation unit was approximately $5 \Omega$, main component of this value was the rod resistance. A $20 \mu \mathrm{F}$ capacitor bank connected carbon electrodes was used to initiate the shunting arc. Rogowskii-type current transformer (Pearson Current Monitor 110A) and high-voltage probe (Tektronix P6015A) were used to measure the circuit current and voltage between the carbon electrodes. The signals were digitized and memorized in a digital oscilloscope (Tektronix TDS504C).

For film preparation using the carbon shunting arc plasma, a disk target with $64 \mathrm{~mm}$ diameter and $11 \mathrm{~mm}$ thickness was set at about $100 \mathrm{~mm}$ away from the carbon rod. Chips of silicon were mounted on the target. In order to extract ions from the plasma to a target, a negative high voltage pulse was applied to the target synchronizing with the generation of the shunting arc. The timing of applying negative bias pulse is important in PBII\&D technique because the target is necessary to be immersed in the high density plasma at applying the bias pulse to achieve high dose ion flux with narrow ion matrix sheath around the target ${ }^{(12)}$. The delay time between the shunting arc generation and the high voltage pulse application was controlled by delay pulse generator and fixed to $100 \mu \mathrm{s}$. The target voltage and current through the target were measured using a high-voltage probe (Tektronix P6015A) and current transformer (Pearson Current Monitor 2877), respectively. Chemical bonds of the films prepared by the shunting arc were analyzed by X-ray photoelectron spectroscope (Shimadzu Cooperation, ESCA-3400).

\section{Exrerimental Results}

3.1 Electrical Properties of Shunting Arc Figure 2 shows a photograph of a light emission from the shunting arc plasma in ambient nitrogen pressure of $2 \mathrm{~Pa}$. The detail of the self-magnetically driven of shunting arc in vacuum is described elsewhere ${ }^{(7)}$. The plasma produced around the rod is driven along the carbon rail electrodes and reached to the target.

Figure 3 shows the waveforms of the current through the carbon rod and the voltage between the carbon electrodes without (Fig. 3(a)) and with (Fig. 3(b)) ambient nitrogen gas at charging voltage

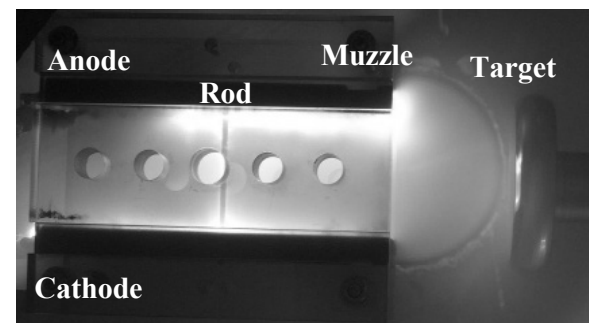

Fig. 2. Photograph of shunting arc discharge at $2 \mathrm{~Pa}$ ambient $\mathrm{N}_{2}$ gas pressure

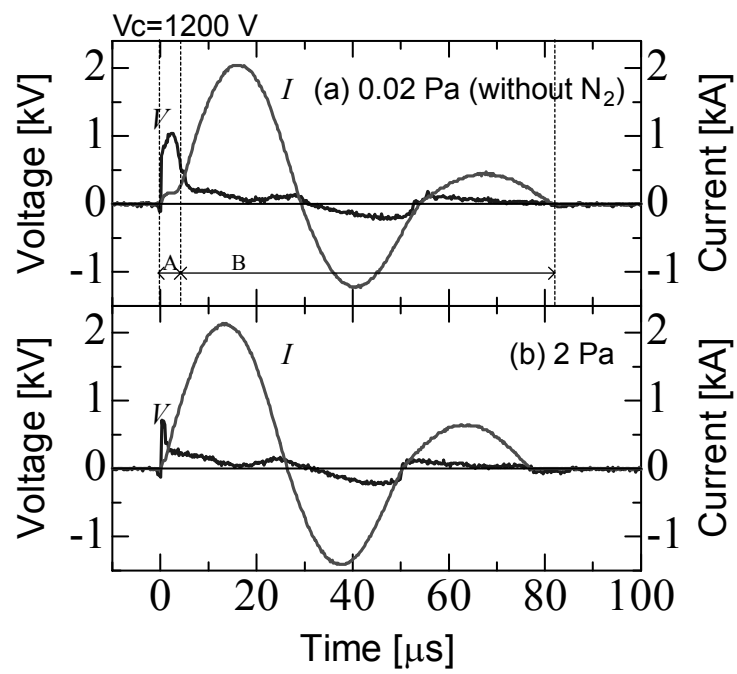

Fig. 3. Typical voltage and current waveforms for two different ambient $\mathrm{N}_{2}$ gas pressures

of $1.2 \mathrm{kV}$. The waveforms in Fig. 3 show a typical feature of shunting arc i.e. these waveforms can be divided in to two regions of $\mathrm{A}$ and $\mathrm{B}^{(2)}$. In the region $\mathrm{A}$, the voltage between the carbon electrodes rises to $1100 \mathrm{~V}$ in $2.2 \mu \mathrm{s}$ as the rod is heated by the release of capacitor energy. During this region, a current of about 170 A flows through the rod. In the region B, the voltage abruptly decreases from 1100 to $200 \mathrm{~V}$ within $2.2 \mu$ s at about $6.5 \mu$ s after switch-on, the abrupt decrease of the voltage is accompanied by a rapid (abrupt) increase in the current. These rapid changes of the voltage and the current indicate the initiation of the shunting arc. The current through the carbon rod is damping oscillation with duration until about $80 \mu$ s and its peak current is about $2.1 \mathrm{kA}$ at $17 \mu \mathrm{s}$. This is due to LC oscillation from the capacitor and the inductance of the wiring of present system. Resistance and inductance of circuit estimated from current waveform in this region is $0.12 \Omega$ and $2.7 \mu \mathrm{H}$, respectively. The resistance is of much lower than that of the carbon rod. Therefore, this value is estimated to be plasma resistance generated by the shunting arc.

The rod heating duration with $2 \mathrm{~Pa}$ nitrogen gas is much shorter than that without nitrogen gas as shown in Figs. 3(a) and (b). The difference is caused a change of the breakdown voltage as a function of ambient gas pressure (Paschen's law). The peak circuit current with nitrogen gas is almost the same as the value without nitrogen gas, and is around $2 \mathrm{kA}$.

Figure 4 shows the charging voltage dependencies of the rod heating energy of the rod and the total energy consumed in the shunting arc. Time dependencies of energy consumed in shunting 


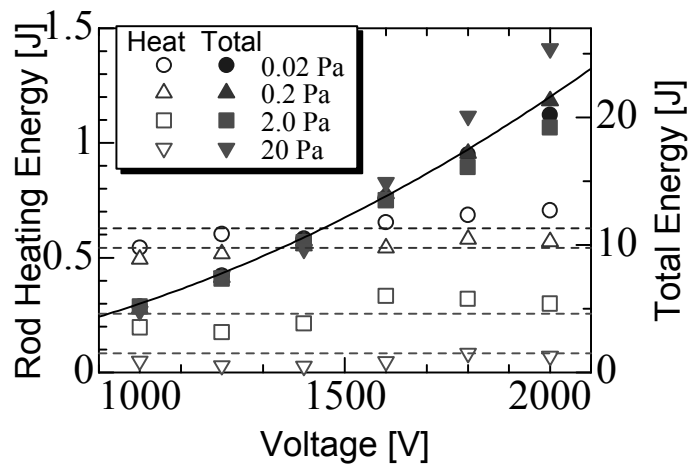

Fig. 4. Energy versus capacitor charging voltage for various $\mathrm{N}_{2}$ gas pressures

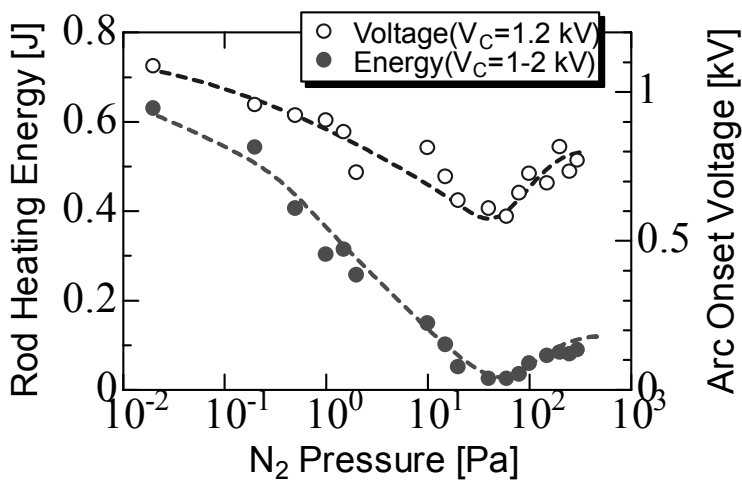

Fig. 5. Arc onset voltage and heating energy as a function of $\mathrm{N}_{2}$ gas pressure

arc are expressed as a time integration of a power that is calculated from waveform of the voltage and the current as shown in Fig. 3. The rod heating energies are calculated by integrating consumed power from voltage on to arc ignition shown as region A in Fig. 3(a). Dotted lines show average values of the rod heating energy for various ambient gas pressures. The rod heating energy is almost independent of the capacitor charging voltage and decreases from 0.62 to $0.08 \mathrm{~J}$ with increasing ambient nitrogen gas pressure from 0.02 to $20 \mathrm{~Pa}$, whereas the total consumed energy is almost independent of the gas pressure and increases with the charging voltage. The total consumed energy is almost on $63 \%$ line of the stored energy in the capacitor at all gas pressure cases. The total consumed energy, which is supplied from the storage capacitor, is constant for various ambient pressures and the ratio of total consumed energy to storage energy in the capacitor is almost $63 \%$ under the present experimental condition.

Figure 5 shows the rod heating energy to generate shunting arc and the onset voltage of the shunting arc as a function of ambient nitrogen gas pressure. The values of the energy was obtained as average values through six time measurements with changing the voltage charged in the capacitor from 1.0 to $2.0 \mathrm{kV}$ in each pressure. The rod heating energy and the arc onset voltage have $\mathrm{V}$-shape characteristics in pressure range from 0.02 to $100 \mathrm{~Pa}$. The rod heating energy decreases from 0.63 to $0.024 \mathrm{~J}$ with increasing gas pressure from 0.02 to $40 \mathrm{~Pa}$ in Paschen left region, and then increases to about $0.058 \mathrm{~J}$ with increasing gas pressure to $100 \mathrm{~Pa}$. The arc onset voltage of the shunting arc at charging voltage of $1.2 \mathrm{kV}$ changes from 1.1 to $0.6 \mathrm{kV}$ with increasing gas pressure

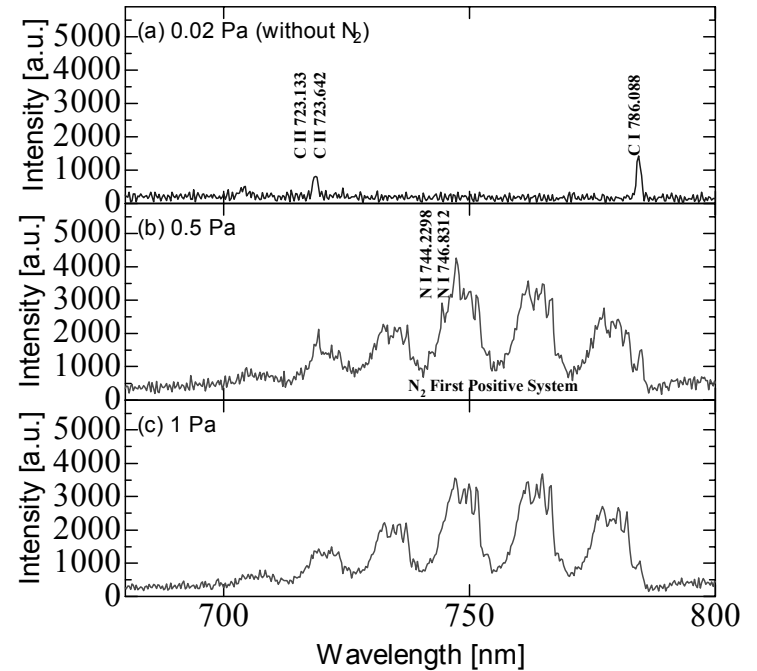

Fig. 6. Emission spectra of shunting arc for three different ambient $\mathrm{N}_{2}$ gas pressures

from 0.02 to $60 \mathrm{~Pa}$, and then increases from $0.6 \mathrm{kV}$ minimum value to $0.8 \mathrm{kV}$ with increasing gas pressure to $300 \mathrm{~Pa}$. The breakdown voltage between the electrodes has minimum value at around $40 \mathrm{~Pa}$ at $40 \mathrm{~mm}$ gap length i.e. the carbon rod length under the experimental condition as shown in Fig. 5. The shunting arc is estimated to ignite by evaporated carbon particles and/or thermoelectrons ${ }^{(13)}$. The increase of the rod heating energy with decreasing nitrogen gas pressure lower than $40 \mathrm{~Pa}$ indicates that more particles and/or electrons are necessary to ignite the shunting arc discharge. The increase of the road heating energy with increasing gas pressure higher than $40 \mathrm{~Pa}$ also indicates that more electrons are required to trigger the discharge owing to a short mean free path.

3.2 Spectrum of Light Emission from Plasma Figure 6 shows the time-integrated spectral lines of the shunting arc discharge for various ambient nitrogen gas pressures. Singly carbon ion line and neutral lines are observed at ambient pressure of $0.02 \mathrm{~Pa}$, i.e., without nitrogen gas. With injecting nitrogen gas to the chamber, first positive system of nitrogen and singly nitrogen neutral lines are observed at $0.5 \mathrm{~Pa}$. However, the atomic nitrogen neutral lines decrease with increasing nitrogen gas pressure and the nitrogen molecular lines are increased to be dominant at the ambient nitrogen gas pressure of $1 \mathrm{~Pa}$ as shown in Fig. 6(c). These results indicate that the nitrogen molecular are excited and dissociated with the shunting arc discharge. The nitrogen molecular excitation and dissociation are considered to be caused by as thermal process and collisions with electrons and carbon ions. However, the electron collisions are dominant because of gas pressure dependency under the present experimental conditions ${ }^{(4)}$. From these results, the shunting arc produced plasma contains excited molecules and atoms of the ambient nitrogen.

3.3 Ion Extraction Figure 7 shows the waveforms of the target voltage and current for two different ambient nitrogen gas pressures at $100 \mu$ s delay time from the arc ignition. A pulse voltage of $2 \mathrm{kV}$ with negative polarity is applied to the disk target immersed in the shunting arc plasma. The charging voltage is set to be $1.2 \mathrm{kV}$. The target current consists of three components as following equation ${ }^{(14)}$, 


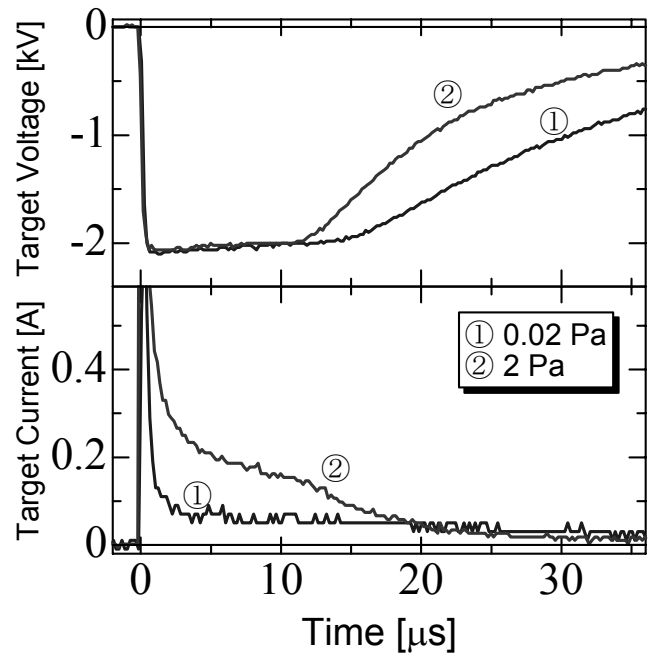

Fig. 7. Target voltage and target current waveforms for two different ambient $\mathrm{N}_{2}$ gas pressures

$$
I_{t}=\frac{d}{d t}\left[c(t) \cdot V_{b}(t)\right]+\left(1+\gamma_{i}\right) I_{i}
$$

where $c$ is the capacitance of the sheath around the target, $V_{b}$ is the applied bias voltage, and $\gamma_{i}$ is the secondary electron emission coefficient by ion impact ${ }^{(15)}$. The target current by applying pulse bias voltage has a sharp peak, which appears almost simultaneously at the voltage application, followed by a stationary state. The initial peak is owing to the capacitive component of the current owing to the matrix sheath formation. The current of the target reaches to the steady state around $10 \mu \mathrm{s}$ after applying the bias voltage. The stationary current at $10 \mu$ s changes from 40 to $144 \mathrm{~mA}$ by injecting the nitrogen gas of $2 \mathrm{~Pa}$. This result reveals that the injected nitrogen molecules are ionized by colliding with carbon ion accelerated in sheath around the target.

3.4 Characteristics of Carbon Nitride Films Figure 8 shows the $\mathrm{C}(1 \mathrm{~s})$ and $\mathrm{N}(1 \mathrm{~s})$ XPS spectra of the prepared carbon films for two different ambient nitrogen gas pressures. The charging voltage to generate the shunting arc is $1.2 \mathrm{kV}$. The pulse voltage of $2 \mathrm{kV}$ with negative polarity is applied to the disk target. The films are deposited with the 500 shots plasma production. With injecting nitrogen gas, the energy at $C(1 \mathrm{~s})$ peak shifts from binding energy (BE) of $\mathrm{C}-\mathrm{C}$ to that of $\mathrm{sp}^{2} \mathrm{C}-\mathrm{N}$ and $\mathrm{sp}^{3} \mathrm{C}-\mathrm{N}$. The peak in $\mathrm{N}(1 \mathrm{~s})$ spectrum appears by employing nitrogen as ambient gas. It is found that when the carbon shunting arc is generated in nitrogen gas, the prepared carbon film contains nitrogen.

Figure 9 shows $\mathrm{C}(1 \mathrm{~s})$ and N(1s) XPS spectra of carbon films deposited at ambient nitrogen gas pressure of $2 \mathrm{~Pa}$. The peak in the $\mathrm{C}(1 \mathrm{~s})$ can be resolved into three components, each being a mixture of a Gaussian curve. The carbon peaks at the $\mathrm{BE}$ approximately $284.6 \mathrm{eV}, 285.9 \mathrm{eV}$ and $287.7 \mathrm{eV}$ correspond $\mathrm{C}-\mathrm{C}$, $\mathrm{sp}^{2} \mathrm{C}-\mathrm{N}$, and $\mathrm{sp}^{3} \mathrm{C}-\mathrm{N}$, respectively ${ }^{(16)}$. The peak in the $\mathrm{N}(1 \mathrm{~s})$ spectrum is deconvoluted into two peaks at the $\mathrm{BE} 400.0 \mathrm{eV}$ and $398.5 \mathrm{eV}$ corresponded $\mathrm{N}-\mathrm{sp}^{2} \mathrm{C}$ and $\mathrm{N}-\mathrm{sp}^{3} \mathrm{C}$, respectively ${ }^{(14)}$. From quantification using relative sensitivity factor method, N/C ratio of film prepared in ambient pressure $2 \mathrm{~Pa}$ is 0.35 ; this value is smaller compared with 1.33 as the ratio of $\mathrm{C}_{3} \mathrm{~N}_{4}$. The role of atomic nitrogen is key factor for the preparation of $\mathrm{CN}_{\mathrm{x}}$ films ${ }^{(16)-(18)}$. It is necessary to increase a number density of the
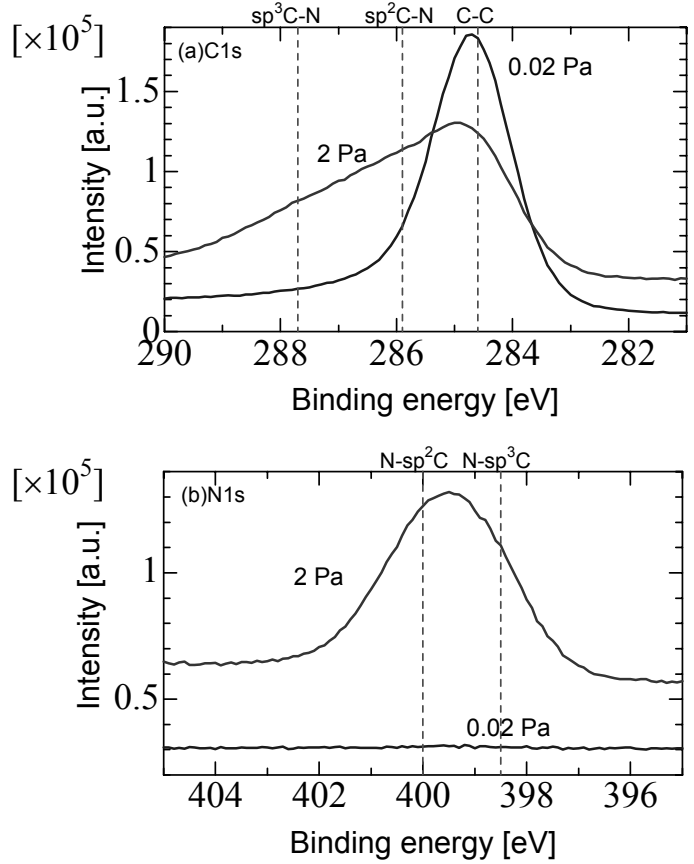

Fig. 8. XPS spectra of the $\mathrm{CN}_{\mathrm{x}}$ films prepared at different ambient $\mathrm{N}_{2}$ gas pressures
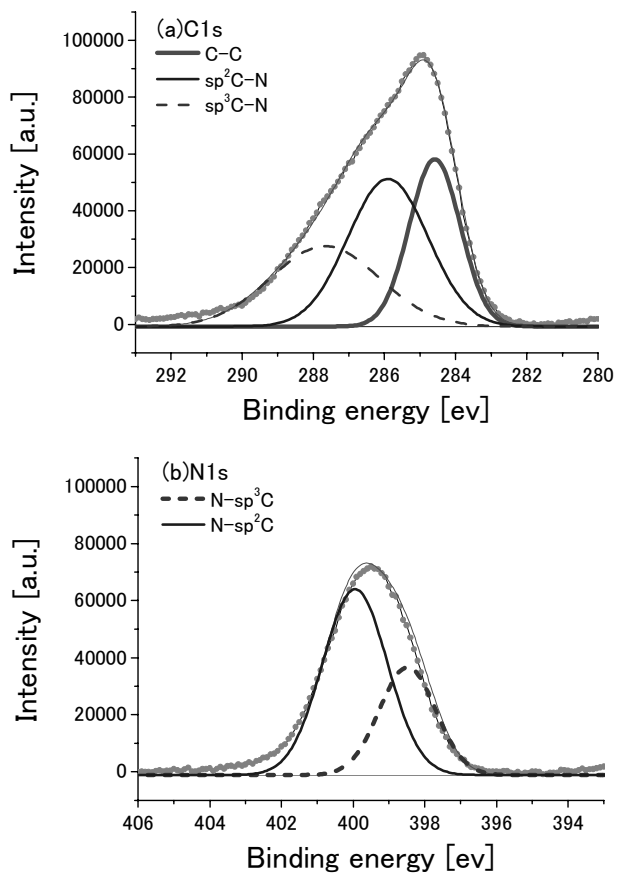

Fig. 9. Deconvolution of the XPS peaks of $\mathrm{CN}_{\mathrm{x}}$ film prepared at $\mathrm{N}_{2}$ gas pressure of $2 \mathrm{~Pa}$

atomic nitrogen contained in the source plasma for improvement of the $\mathrm{N} / \mathrm{C}$ ratio.

\section{Conclusions}

The shunting arc plasma is produced in nitrogen gas circumstance. The rod heating energy to generate the shunting arc has minimum value for the variation of ambient gas pressure. The total energy consumed in shunting arc is almost independent of the 
gas pressure and increases with the charging voltage. With injection of the nitrogen gas, the shunting arc plasma contains excited molecules and atoms of the ambient nitrogen. The ion current extracted from the plasma increases with the increasing in the ambient gas pressure from 0.02 to $2 \mathrm{~Pa}$. The carbon films prepared using shunting arc in nitrogen gas circumstance contain nitrogen with $\mathrm{N} / \mathrm{C}$ ratio of 0.35 at $\mathrm{N}_{2}$ pressure of $2 \mathrm{~Pa}$.

\section{Acknowledgments}

The authors thank Mr. Y. Shida of Iwate University for technical supports. The authors thank Mr. T. Murakami of Iwate University for his helps. This work was supported by Grants-inAid for Scientific Research (JSPS No. 18340181).

(Manuscript received Nov. 28, 2006, revised April 13, 2007)

\section{References}

(1) K. Yukimura and K. Takaki : IEE Trans. FM, Vol.123, No.10, pp.652-655 (2003)

(2) K. Yukimura and S. Masamune : "Shunting Arc Generation of a Heated Wire in a Low Pressure Gas", T. IEE Japan, Vol.118-A, No.9, pp.954-958 (1998)

(3) K. Yukimura and S. Masamune : "Shunting arc plasma generation over a wide range of ambient pressure and ion extraction", Rev. Sci. Instrum, Vol.73, pp.860-862 (2002)

(4) K. Yukimura, K. Yoshida, and Y. Tani : "Carbon shunting arc and its induced plasma”, Rev. Sci. Instrum., Vol.71, pp.1184-1186 (2000)

(5) T. Monguchi, R. Isono, K. Yoshioka, K. Yukimura, and S. Masamune : "Carbon Shunting Arc Generation and DLC Deposition", T. IEE Japan, Vol.119-A, No.5, pp.609-614 (1999)

(6) K. Yukimura, M. Kumagai, H. Saito, M. Kohata, and K. Takaki : "Deposition of amorphous carbon using a shunting arc discharge", Surf. Coat. Technol., Vol.174-175, pp.1187-1190 (2003)

(7) K. Takaki, R. Hasegawa, S. Nakamura, S. Mukaigawa, T. Fujiwara, M. Kumagai, and K. Yukimura : "Self-magnetic drive of a shunting arc", Surf. Coat. Technol., Vol.186, No.1-2, pp.182-186 (2004)

(8) K. Yukimura, M. Kumagai, K. Takaki, R. Hasegawa, S. Nakamura, S. Mukaigawa, and T. Fujiwara : "High deposition rate of amorphous carbon film using a magnetically driven shunting arc discharge", Surf. Coat. Technol., Vol.196, No.1-3, pp.203-206 (2005)

(9) K. Takaki, O. Kumagai, R. Hasegawa, S. Mukaigawa, T. Fujiwara, M. Kumagai, and K. Yukimura : "Characteristics of magnetically driven shunting arc plasma for amorphous carbon film deposition", Thin Solid Films, Vol.506-507, pp.150-154 (2006)

(10) K. Yukimura, N. Tenno, and S. Masamune : "Carbon shunting arc in RF nitrogen plasmas - a basic study on plasma-based ion implantation", Vacuum, Vol.65, pp.341-346 (2002)

(11) A. Y. Liu and M. L. Cohen : "Structural properties and electronic structure of low-compressibility materials: $\beta-\mathrm{Si}_{3} \mathrm{~N}_{4}$ and hypothetical $\beta-\mathrm{C}_{3} \mathrm{~N}_{4}$ ", Phys. Rev. B, Vol.41, pp.10727-10734 (1990)

(12) A. Anders : "Plasma and ion sources in large area coating: A review", Surf. Coat. Technol., Vol.200, pp.1893-1906 (2005)

(13) K. Takaki, S. Mukaigawa, T. Fujiwara, and K. Yukimura : "Shunting arc-produced hybrid plasma and its magnetic drive for PBII\&D", Surf. Coat. Technol., Vol.201, pp.6490-6494 (2007)

(14) K. Takaki, S. Mukaigawa, T. Fujiwara, M. Kumagai, and K. Yukimura : "Ion extraction from carbon shunting arc plasma", Appl. Phys. Lett., Vol.82, No.16, pp.2583-2585 (2003)

(15) M. Shamim, J. T. Scheuer, R. P. Fetherston, and J. R. Conrad : "Measurement of electron emission due to energetic ion bombardment in plasma source ion implantation", J. Appl. Phys., Vol.70, No.9, pp.4756-4759 (1991)

(16) M. Itoh, Y. Suda, M. A. Bratesscu, Y. Sakaki, and K. Suzuki : "Amorphous carbon nitride film preparation by plasma-assisted pulsed laser deposition method", Appl. Phys. A, Vol.79, No.4-6 pp.1575-1578 (2004)

(17) J. Bulir, M. Novotny, M. Jelinek, J. Lancok, Z. Zelinger, and M. Trchova : "Pulsed laser deposition of $\mathrm{CN}_{\mathrm{x}}$ films: role of r.f. nitrogen plasma activation for the film structure formation", Diamond \& Related Materials., Vol.11, pp.1223-1226 (2002)

(18) R. Ohta, T. Yokota, V. Anita, N. Saito, and O. Takai : "Synthesis of nitrogen-rich carbon nitride thin films via magnetic field-assisted inductively coupled plasma sputtering", Vacuum, Vol.80, pp.752-755 (2006)
Keigo Imanishi

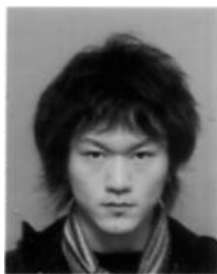

Osamu Kumagai

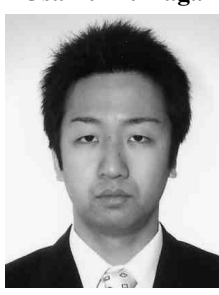

Seiji Mukaigawa

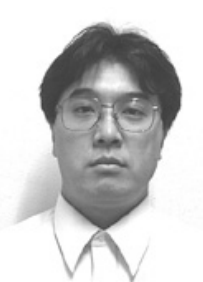

(Student Member) was born in Hokkaido, Japan, on December 26, 1983. He graduated from Department of Electrical Engineering, Asahikawa National College of Technology, Japan, in 2004, and received the B.Eng. degree in electrical engineering from Iwate University, Japan, in 2006. He is now in graduate course in electrical engineering of Iwate University, Japan.

(Non-member) was born in Iwate, Japan, on August 12, 1981. He received the B.Eng. and M.Eng. degrees in electrical engineering from Iwate University, Japan, in 2004 and 2006, respectively. In 2006, he was in the Hitachi Plant Technologies Co., Inc., Japan.

Electronics Engineering, Iwate University, Morioka City Japan, as Research Associate.
Koichi Takaki

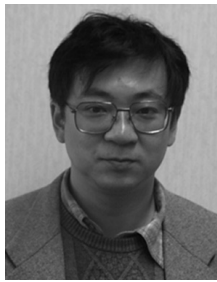

(Member) received the B.Sci. degree from Ibaraki University, Mito, Japan, in 1993, and the M.Sci. and Dr.Sci. degrees from Hiroshima University, Higashi-Hiroshima, Japan, in 1995 and 1998, respectively, all in physics. In 1998 and 2001, he was with the Research Center of Nanodevices and Systems, Hiroshima University, as a Postdoctoral Fellow. Since 2001, he has been with the Department of Electrical and University, Morioka City Japan, as a Research Associate. During 2000-2001, he was with McMaster University, Hamilton, ONT, Canada, as a Visiting Scientist. Since 2001, he has been with Iwate University, as an Associate Professor. His current research interests include pulsed-power technology, such as development of a new plasma source for solid materials, pulsed-ion technology, such as three-dimensional ion implantation technology, and exhaust gas processing in atmospheric pressure, such as reduction of $\mathrm{NO}_{\mathrm{x}}$, decomposition of perfluorinated compounds (PFCs), and ozone generation.

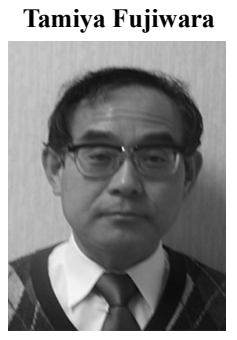

(Member) received the B.Eng., M.Eng. and Dr.Eng. degrees from Tohoku University, Sendai, Japan, in 1971, 1973 and 1986, respectively, all in electrical engineering. From 1987 to 1988 , he was with the Massachusetts Institute of Technology, Cambridge, as a Visiting Scientist. In 1994, he joined Iwate University, Morioka, Japan, as a Professor, where he has worked on phenomena and applications of gas discharge. His current research interests include generation of discharge plasma at atmospheric pressure. 
Ken Yukimura (Member) was born in Nagasaki, Japan, on February 11,

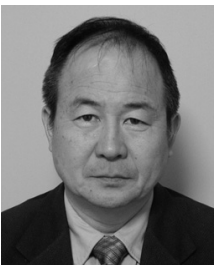

1948. He received the B.Eng., M.Eng. and Dr.Eng. degrees from Doshisya University, Kyoto, Japan, in 1970, 1972 and 1977, respectively, all in electrical engineering. In 1977, he joined the Faculty of Engineering, Doshisya University, where he was a Research Associate from 1977 to 1979, an Associate Professor from 1986 to 1992, and has been Professor since 1992. His current research interests include pulsed-power technology, such as development of a new plasma source for solid materials, pulsed-ion technology, such as three-dimensional ion implantation technology, and exhaust gas processing in atmospheric pressure, such as decomposition of $\mathrm{NO}_{\mathrm{x}}$.
Yoshiyuki Suda (Member) He was born in Nagoya, Japan, on

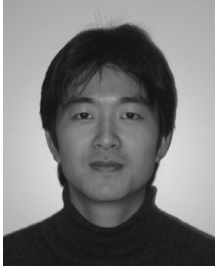

November 18th 1971 and received the B.Eng., M.Eng., and Dr.Eng. degrees in 1994, 1997, and 2006, respectively, from Hokkaido University. He worked for Paloma Industries, Inc. as an engineer. In 1998, he became an Instructor at Graduate School of Engineering, Hokkaido University. Since 2004, He has been on Graduate School of Information Science and Technology, Hokkaido University. 